\title{
The Application of Engineering Thinking in the Teaching Management of Artistic Design
}

\author{
Lin Bo \\ Xiamen University Tan Kah Kee College \\ Zhang Zhou, China \\ wellyuki@126.com
}

\begin{abstract}
Under the dual premise of respecting artistic design teaching rules and management norms and efficiency, the teaching management level of artistic design department is improved and the efficiency of artistic design teaching is finally improved. This paper takes engineering thinking as the internal element of the management characteristics, systematically and deeply studies the constraints and solutions of teaching organization and management and teaching and curriculum reform of artistic design major, and then concludes that we must use rigorous and rational engineering thinking which reflects systematism and logicality to guarantee the effectiveness of artistic design education.
\end{abstract}

Keywords-Engineering Thinking; Artistic Design Education; System Capability; Management

\section{INTRODUCTION}

Higher design education in China is developed under the historical background of the rapid development of commercial culture and economic system transformation. The high expectation of the design industry brings the attention to the design education. The upsurge of setting design major in colleges and universities all over the country has been continuing since a period of time. The impetuous effect and inefficiency brought about by blind follow-up and hasty running schools have caused the reflection of academic circles and various related levels. In terms of colleges and universities, how to effectively train artistic design talents with strong professional ability, practical innovation ability and adaptability to the environment is a problem that must be solved. In addition, how to realize the effective management of artistic design education is also a new research field. The problem that this paper is going to explore and study is how to explore the complementary effects of the particularity of engineering thinking and design education, so as to make it actively support and promote the management of artistic design education and finally improve the efficiency of running of the education of artistic design with the combination with pedagogy, cybernetics, management, artistic design, and other fields of science and engineering.

\section{THEORETICAL BASIS AND PRACTICAL SIGNIFICANCE}

The creation of artistic design encourages novelty and creativity, and the teaching of artistic design also has its own particularity. However, the management of artistic design education should be a rigorous, non-emotional system engineering. The so-called "artistic design teaching special but artistic design teaching management is not special". The engineering thinking, mentioned in this paper, is different from the artistic perceptual thinking system. It is rational and comprehensive thinking, which emphasizes on logicality and objectivity.

Combining with the experience and problems of artistic design teaching in some colleges and universities in China, it is the basis of this subject to introduce engineering thinking into the teaching management of artistic design and emphasize the integrity, logic and rationality.

\section{THE PRESENT SituATION OF EDUCATIONAL}

DEVELOPMENT PRACTICE AND RESEARCH ON THE DESIGN FIELD

In our country, the attention paid to the arts in the educational circles does not match the demands of the artists. In the division of disciplines, art has long been subordinate to the literary category. It wasn't until March 2011 that art was promoted into a subject (before that, it belongs to literature) and design became a first-level subject under this category. It was clearly defined in "the Undergraduate Special Catalogue of Higher Institutions" (2012 edition) that the undergraduate majors under the design science category include artistic design (13501), Visual Communication Design (13502), Environmental Design (13503), Product Design (13504), Clothing and Clothing Design (13505), Public Art (13506), Arts \& Crafts (13507), Digital Media Art (13508), Art and Science \& Technology (13509T), nine majors in total.

At present, there are many researches and expositions on artistic design education in our country, focusing on the concept of artistic design education, teaching methods, innovation of design talents, optimization of teaching resources and integration with traditional culture and modern society. However, there are few researches on the management of higher education of artistic design as a systematic system. Especially, the attempt to integrate engineering thinking into the management of artistic design education is still a blank. 
This paper analyzes the practice of running a school of artistic design discipline in recent years and tries to explore and fully respect positive effects and application prospects by using the characteristics of engineering thinking (integrity and strictness) in educational management under the law of artistic design education. This paper summarizes how to integrate and complement the particularity of artistic design education and the strictness of engineering thinking in order to realize the university and the optimization of artistic design education management under the flexible and independent college running mode. To some extent, it fills the blank of artistic design education management

The Incheon Declaration outlined the development vision of global education in 2030 as "ensuring inclusive, equitable and quality education and promoting lifelong learning opportunities for all" It was further summed up and believed that the core problem of China's higher education in the next 15 years is the matching between the educational concept and the educational reform and development situation under the stage of popularization of higher education in China. Besides (Pan Maoyuan\&Li Guoqiang, 2016) [1], the idea of popularizing higher education in 2030, was summed up by them as "all in" and "new quality".

With the comprehensive development of Chinese politics, economy and culture, the connotation of the city need to be improved and people have the need to improve the quality of life and spiritual enjoyment(Wang Xiaofen,2014) [2]. Therefore, the significance of the discipline of design, which is closely related to people's daily lives, to social and economic development is self-evident. It is a discipline that plays a decisive role in enhancing the added value of products and aesthetic quality. The society is transitioning from an industrial society to an information society and then a knowledge society. In the fierce market competition, the function of artistic design is further enlarged., Whether from international aspect or from domestic aspect, the improvement of the level of design (which only refers to the narrow sense of "artistic design") is one of the main means to enhance competitiveness (Yu Xue \& Dong Qingtao, 2011) [3]. It is particularly important and crucial for Chinese to improve design level and to develop their own design brands. At this time, the lagging contradiction of the development of design subject education is more prominent. It is because that the development of the design discipline is late and it has always been subordinate to the art discipline. Even now that higher education has become popular, the development of the design discipline is still weak compared with other disciplines. This is not only affected by the social and economic development of China's environment, but also by internal factor about the positioning of design discipline is not accurate (mode of design education, student pool disputes, ideas conflicts, and so on).

In my opinion, the main problems in the development of design subject education are similar, and there are only some characteristics: the educational concept of design discipline is in fact contradictory. On the one hand, it advocates to explore the laws of design discipline itself and makes compensation for the congenitally deficient of the late development of the major, on the other hand, it takes the traditional elite education method as the standard, which limits the multi-dimensional quality evaluation of the design major which belongs to the crossdiscipline. In addition, the misunderstanding of creative teaching leads to the criterion of design creation (which is different from artistic creation), which is multi-dimensional with the organizational form of studio, workshop and project. However, there is no process evaluation system for it. Moreover, in this form, "reform and innovation", evaluation (standard) and essence (effect) are the traditional contradictory teaching ideas. It forms the bottleneck of the development of design subject in higher education.

\section{A. The key problems and innovations of engineering thinking in teaching management of artistic design}

- Changing the thinking of "special" artistic design creative practice teaching management with the rational and strict logic of engineering, and studying from the dimension of promoting and complementing the role of holistic and global thinking to the education management of artistic design.

- Connecting management, art, design, logic and cybernetics to explore the system of promoting factors for optimizing the management of artistic design education.

- Combing the new development opportunity of the practice teaching of modern creative design in our country and the present situation of high demand for creative design talents under the economic condition of modern creative industry, as a starting point, to open up a research field with far-reaching practical significance.

- Comprehensively analyzing and researching on the current teaching management system of artistic design in most colleges and universities in China, to prepare for the establishment of an educational management system of artistic design with "standardization and innovation, coexistence of efficiency and characteristics".

\section{The Misunderstanding OF CREATIVE TEACHING IN DESIGN DISCIPLINE}

Like other disciplines, innovative teaching in design discipline also needs to go beyond a series of misunderstandings: the idea of advanced teaching methods, diverse organizational forms (workshop and studio respected by many design schools and organizations), and rich curriculum content replace innovative teaching in universities(Wang Hongcai, Liu Junying, Xie Debo,2016)[4]. In the training of talents in design disciplines, they even praised teaching and business integration (project style) as teaching innovation or believed that the cross and mix of multisubjects is teaching innovation. It is worth pointing out that the cross and mix of multi-subjects in design teaching is the intrinsic innovation attribute of design discipline and cannot be confused with innovative teaching in universities.

In the creative teaching of design discipline, it is worth affirming that because of the practical needs of the connotation, academic orientation and talent training goal of the design subject, it is different from the traditional teaching of other 
disciplines. It is also consistent with one of the ideas of innovative teaching in universities: any knowledge taught in universities must be able to establish a link with the life experience of the students. However, it still does not realize two other ideas of innovative teaching: any knowledge taught by universities must be able to touch the students' inherent knowledge structure, and must be able to establish a link with the students' future career! In the connection of future career, there is one-sided understanding that the teaching of design discipline is to train the professional design talents. This is the narrowing of the education connecting the future career of the university innovation education.

\section{Systematic ABILITy Cultivation OF the PeRIPHERY OF DESIGN DISCIPLINE}

It is proposed that the peripheral competence of the design discipline be defined as the comprehensive ability to adapt to a whole society, beyond the nine undergraduate professional skills covered by the accounting disciplines, and the talents needed in the social industrial chain covered by these specialties. It is different from the unique professional skills and professional knowledge of design talent. include:

Specific professional peripheral competencies should

- Strong ability to collect and capture information;

- Communication ability of coordinate the team with professional and non-professional background;

- Active, healthy, and active personality (high emotion)(Wu Daguang \& Wang Xuhui,2015)[5];

- Good morality and correct aesthetic consciousness;

- Ability to deal with comprehensive problems and complicated contradictions.

\section{CONCLUSION}

In fact, the peripheral competence of the design discipline is a generalization of the comprehensive quality, which includes the ability to connect the industry chain and the ability to assist the professional development. How to cultivate these peripheral competencies must be realized through an effective educational process. In order to ensure the effectiveness of the educational process, it is necessary to apply rigorous, non-perceptual engineering thinking that reflects logic and integrity for the implementation.

Due to the uniqueness that the design practice activities span across science and art, reason and intuition, reasoning and imagination, it is decided that the design discipline should have its own uniqueness. Simon believes that we should break the boundaries of multiple cultures, fields and disciplines, and that the study of design may become an interdisciplinary study of all creative activities that build the human world (Qiu Jingyuan, 2011) [6]. The management level of artistic design education is determined by the general environment and management methods of the colleges and universities. We should take the engineering thinking as the internal element of the management characteristics, start with the difference and connection between the design education and the design education management, and systematically and in-depth study the complementary of engineering thinking and artistic design thinking. It is helpful to realize the improvement of the management level of the artistic design department under the dual premise of respecting the law of artistic design and the law of management, and finally to reform the management style of the department of artistic design. Moreover, it can also provide a new thinking method and decision basis for the further development of creative practice teaching and the creation of a better development space for the teaching of artistic design department.

\section{REFERENCES}

[1] Pan Maoyuan \& Li Guoqiang. The Vision of Chinese Higher Education Modernization by 2030.China Higher Education.2016(17):5-7

[2] Wang Xiaofen. Exploring and Analysing about Subject System of Design Constructing. Art Research. 2014(2):102-103

[3] Yu Xue \& Dong Qingtao. The Circumstances and Change of Artistic Design Education. Journal of Changchun University of Science and Technolo.2011.6(4):153-154

[4] Wang Hongcai, Liu Junying, Xie Debo. University Creative Teaching: Concept, Characteristic and Misunderstanding. China University Teaching.2016(2):19-23

[5] Wu Daguang \& Wang Xuhui. A Review on Several Issues of Higher Education Recent Studies in China. Educational Research.2015(5):73-88

[6] Qiu Jingyuan. On Design Discipline and Design. Design Research.2011(5):19-23 